\title{
What Is the Role of Conservative Antibiotic Treatment in Early Appendicitis?
}

\author{
Inchien Chamisa \\ Mediclinic Medforum Private Hospital, Pretoria, \\ South Africa
}

\section{Introduction}

Acute appendicitis remains a common surgical condition and appendicectomy remains the mainstay of treatment for over 130 years. The first appendicectomy was performed by A. Groves more than a century ago. Following the publication of R. Fitz's classical (1) paper in 1886 on 247 patients with perforated appendicitis, early appendicectomy has been advocated as the standard treatment for early appendicitis. Later, in 1889 McBurney (1) published his study of eight patients with acute appendicitis and further recommended early appendicectomy as optimal management. Since then early appendicectomy has been widely accepted as the best treatment for early appendicitis. $(1,2)$.

However, as the diagnosis of acute appendicitis remains largely a clinical one, diagnostic uncertainty may lead to a delay in treatment or negative surgical exploration, both adding to the morbidity associated with this condition. While antibiotics are indicated in patients with signs of peritonism, their current role in the routine management of early acute nonperforated appendicitis remains debatable.

Over the past two decades, three randomised controlled trials have been published comparing the efficacy of antibiotics alone with that of surgery for selected and unselected patients with that of surgery for acute appendicitis $(3,4$, and 5). It is the aim of this chapter to give a critical analysis of the existing data regarding the non-surgical management of acute appendicitis with special reference to the efficacy, long-term outcome and the selection of patients for conservative treatment.

\section{Pathophysiology of acute appendicitis}

To appreciate the potential role of the conservative approach in the management of acute appendicitis it is essential to have an understanding of the basic patho-physiology of the condition. Acute inflammation of the appendix is associated with obstruction of the appendiceal lumen in 50 to $80 \%$ of patients. The majority are attributed to hyperplasia of sub-mucosal lymphoid follicles and this is commonly seen in children. Other causes include faecolith, parasitic infections (e.g. schistosoma), gallstones, carcinoid tumours and carcinoma of the caecum. As the mucinous secretions accumulate in the lumen, the intraluminal pressure rises and this is sufficient to cause collapse of the draining veins. Once obstruction and ischaemia sets in, this facilitates bacterial proliferation with further inflammatory oedema and exudation, compromising the blood supply. On the other hand, a 
minority of acute appendicitis have no demonstrable luminal obstruction and the pathogenesis of inflammation in this subgroup is largely unknown.

During the early stages, only scanty neutrophilic exudate is evident throughout the mucosa, sub-mucosa and muscularis propria. This results in congestion of the sub-serosal vessels. This stage signifies early acute appendicitis. Later on, prominent neutrophilic exudate forms a fibrino-purulent reaction over the serosa. Further inflammation results in formation of abscesses in the wall together with ulceration and foci of necrosis in the wall resulting in acute suppurative appendicitis. This then progresses to larger areas of haemorrhagic ulceration of the mucosa and gangrenous necrosis through the wall extending to the serosa. This is the acute gangrenous appendicitis stage which rapidly progresses to rupture and suppurative peritonitis. The histological pathognomonic features of acute appendicitis are neutrophilic infiltration of the muscularis, usually accompanied with ulceration and neutrophils in the mucosa.

It is interesting to note that Luckmann et al $(6,7)$ has proposed that the entities of perforated and non-perforated appendicitis are two distinct and different conditions. These authors believe that one form of appendicitis results in early perforation whereas the other one does not perforate and may resolve spontaneously. This begs the question, how do we distinguish these two clinical entities and do they demand the same management?

\section{The concept of conservative management}

The complications of acute appendicitis can be severe and include perforation, generalised peritonitis and intra-abdominal abscesses. Up to $15-30 \%$ of patients operated for suspected appendicitis are found to have a normal appendix on histological examination (8). Since appendicectomy is associated with complications (e.g. wound infections, adhesive small bowel obstruction, pneumonia, hernias ) the possibility of non-surgical treatment has been proposed since the middle of the $20^{\text {th }}$ century. The first report of choosing the conservative management of acute appendicitis over an operation was presented in the British Medical Journal in1945 by McPherson and Kinmonth (9). Then in 1959 Coldrey (2) studied and reported on 471 unselected patients who had antibiotic treatment alone with acceptable mortality and morbidity rates. In 1977 a study was published from China which described 425 patients managed with a combination of antibiotics and traditional Chinese medicine and at follow up a recurrence of $7 \%$ was found (10). The conservative treatment with antibiotics was described in nine USA submariners in 1990 with encouraging results but this was in a situation where surgery was not safely available. (11)

\section{Background}

Diagnostic un-certainty in those with suspected appendicitis may result in delayed treatment or negative explorations sometimes associated with complications. Populationbased studies have shown that there are significant long-term risks associated with surgical explorations for appendicitis (12). The risk of small bowel obstruction needing surgical intervention has been shown to be around $1.3 \%$ by 30 years. (13) It is of interest that a negative appendicectomy has been shown to have more complications compared with a positive appendicectomy especially the risk of small bowel obstruction (14). It is because of these concerns that in recent years there has been a heightened interest in the use of antibiotic therapy as the primary treatment for patients with uncomplicated appendicitis. It 
is still uncertain as to what extend these promising results of conservative management of acute appendicitis are in unselected populations.

Traditionally, patients with no overt clinical signs such as right iliac fossa guarding and peritonism are monitored and re-assessed for any changes in clinical signs with or without commencing antibiotic therapy. The place of routine antibiotic treatment in patients presenting with acute non-perforated appendicitis is still a debatable issue. Other studies have concluded that antibiotic therapy reduces the rate of wound and intra-abdominal sepsis following surgery $(15,16)$.

\section{Conservative management compared with appendicectomy}

Appendicectomy has been regarded as the principal procedure for patients presenting with acute appendicitis since the first appendicectomy was performed by A. Grooves more than 130 years ago. The mortality rate for emergency appendicectomy ranges from $0.07 \%$ to $0.7 \%$ in patients without perforation and $0.5 \%$ to $2.4 \%$ in those with (6). The chances of death in patients undergoing an emergency appendicectomy for acute appendicitis is up to seven times that of the general population of the same age and gender (17). The post-operative morbidity following emergency appendicectomy is 10 to $19 \%$ in those without perforation and reaches 12 to $30 \%$ in patients with a perforation (18). It has been shown that the operative morbidity following appendicectomy for a normal appendix in patients with suspected acute appendicitis is similar to that in patients with non-perforated appendicitis (19).

\section{Financial costs}

Over and above the human costs of operative morbidity and mortality, there is a significant financial burden associated with appendicectomy. The overall cost of appendicitis in the United States in 1997 was estimated as one million hospital days and \$3 billion in hospital charges, of which postoperative morbidity accounted for $50 \%$ of the charges (17) The costs are expected to rise further with the advent and popularity of laparoscopic appendicectomy.

\section{Antibiotic resistance}

The availability of monotherapy for effective treatment of intra-abdominal infection has made triple-regimen antibiotics almost obsolete. Furthermore, new effective oral antibiotics are now available which allow treatment of serious infections on an outpatient basis. Because of these advances in antibiotic therapy, surgeons have considered the possibility of treating acute appendicitis with antibiotics alone with the hope of replacing urgent appendectomy in a selected group of patients.

Despite the recent improvements in medical technology, the perforation rate for acute appendicitis has remained almost unchanged since the 1980s, ranging from 20 to $30 \%$. This apparent constant perforation rate supports Lachmann's hypothesis that perforated and non-perforated appendicitis represent two different disease processes.

There is sonographic evidence in the literature supporting the spontaneous resolution of acute appendicitis (20) managed conservatively. The widely believed theory of disease progression from mucosa to serosa to perforation may not apply in all cases of acute appendicitis as supported by Lachmann and colleagues. 
This chapter includes all the randomised controlled trials and other studies on which patients over 18 years with suspected acute appendicitis were randomised to antibiotic therapy alone or surgery at initial presentation. The primary outcome measures of most of these randomised controlled trials was complications such as reoperation, tra-abdominal abscess, small bowel obstruction, wound dehiscence, incisional hernia, deep venous thrombosis, pulmonary embolism, cardiac complications and the need for ileo-caecal resection. The minor complications included prolonged post-operative recovery, urinary dysfunction, anaesthesia-related complications, diarrhoea, clostridium difficile infection, fungal infection and wound sepsis. Secondary outcome measures included duration of hospital stay and re-admission rates.

\section{Efficacy}

It is important to bear in mind that the conservative management of acute appendicitis has several safety implications which need to be taken into consideration. The act of delaying surgical intervention may increase the risk of appendiceal perforation, intra-abdominal abscesses and localised or generalised peritonitis. On the other hand, appendicectomy is associated with significant morbidity which includes wound sepsis, incisional hernias and adhesive small bowel obstruction.

Several recent literature reports which include randomised controlled studies, metaanalyses and prospective studies comparing conservative management and appendicectomy for acute appendicitis in selected patients have concluded that the former is effective with a reported success rate ranging from $68 \%$ to $95 \%(21,3)$. In a randomised clinical trial by Hansson et al (3), the authors found efficacy in the study group according to intention to treat to be $48 \%$ (97 of 202). Out of 119 patients who received antibiotics, eleven (9.2\%) had an appendicectomy owing to clinical progression of the disease within 2436hours. They found that of the 250 patients who had surgical exploration, 223 (89.2 \%) had confirmed appendicitis or another surgical condition. From this they concluded that the primary treatment efficacy was 90.8 per cent for antibiotic therapy compared to 89.2 per cent for those who underwent surgical exploration. However, they found out that after 1 year follow-up, antibiotic treatment efficacy decreased to $78.2 \%$ mainly due to recurrences. The efficacy was significantly lower than in the surgery group $(\mathrm{P}<0.05)$. The minor complications were similar for both groups while major complications were threefold higher in the appendicectomy patients $(\mathrm{p}<0.05)$. Of the operated patients, $2.9 \%$ needed a second operation, $3 \%$ had abscesses, $2.4 \%$ postoperative small bowel obstruction, wound rupture $(1.8 \%)$, pulmonary embolism $(0.6 \%)$, postoperative cardiac dysfunction $(0.6 \%)$ and $1.2 \%$ needed ileo-caecal resection. Anaesthesia-related complications were $1.2 \%$ and the wound infection rate $7.6 \%$. Their readmission rate was $15(13.9 \%)$ after a median of 1 year. A third of these admissions appeared within 10 days of hospital discharge and the other two-thirds between 3 and 16 months after discharge.

In a prospective randomised controlled study by Styrud et al, (4) antibiotic therapy alone was found to be sufficient in the majority of patients with acute appendicitis with only $12 \%$ of patients from the antibiotic group requiring surgery within the next $24 \mathrm{hrs}$. Out of 128 patients managed conservatively, $17(12 \%)$ went on to have surgery within 24 hours. After one year, the recurrence rate was $15 \%$ (16 patients) and they found out many of these patients requested conservative management the second time around. 
In a series of five patients reported by Wiegering et al, the authors concluded that conservative management of acute appendicitis is safe and that it should be considered in patients with neutropaenia who are otherwise clinically stable (22).

Efficiency can be measured by comparing the recurrence or readmission rates of patients managed conservatively to that of complications after appendicectomy. Recurrence rates reported in the literature range from 3 to $25 \%$ within the first year (4). In a recent metanalysis by Varadhan et al, they reported recurrent rates of $15 \%$ in the first year following conservative management on antibiotics (21). It is interesting to note that the perforation rate in patients admitted with a recurrence was not higher compared to those who underwent initial appendicectomy. It is not surprising that the investigators who reported a higher recurrence rate following conservative treatment have advocated that this approach should be considered in patients with a high risk for post-operative complications.

In a meta-analysis by Varadhan et al., out of 350 patients randomised to the antibiotic group, 238 (65\%) were managed successfully on antibiotics alone with 38 recurrences (21). After 1 year follow up, 200 patients from the antibiotic group remained asymptomatic.

A metanalysis of RCTs showed a trend for reduced complications for antibiotic therapy [RR $(95 \% \mathrm{CI}): 0.43(0.16,1.18)]$ ] with no difference between antibiotic therapy and surgery for length of hospital stay.

In a study by Eriksson et al, 40 patients with a sonographic diagnosis of acute appendicitis were randomised to either appendicectomy or antibiotics only therapy (5). They concluded that patients who received nonsurgical treatment did as well as the patients who underwent an appendicectomy.

The conservative management of acute appendicitis has safety implications which should be considered in decision making. This form of treatment has attracted the attention of clinicians because of the growing body of evidence that it eliminates the surgical and anaesthesia-related complications associated with appendicectomy. Possible complications following surgery include accidental enterotomies, post-operative haematomas, colonic fistula, surgical site infection, intra-abdominal abscess, paralytic ileus, adhesive small bowel obstruction and incisional hernias with the possible need for a second operation. The rate of intestinal obstruction is slightly higher after a negative appendicectomy compared to a positive one.

Literature studies have shown that the risk of death for patients undergoing an emergency appendicectomy is approximately seven times that of the general population of the same age and gender (17). The mortality rate for patients undergoing emergency appendicectomy for non-perforated and perforated appendicitis is 0.07 to $0.7 \%$ and $0.5-2.4 \%$ respectively (6). The operative morbidity rates for non-perforated and perforated appendicitis are $20 \%$ and $30 \%$ respectively. (ref $2 . .8,27$ ) The operative mortality rises with increased age as follows: $<0.1 \%$ in patients less than 40 years of age, $2.6 \%$ in patients more than 60 years of age, $6.8 \%$ for octogenerians and $16.6 \%$ for nonagenarians (17).

Hansson et al (3) found that the major complications were not significantly related to open or laparoscopic surgery. The common minor complications were wound infection in the appendicectomy group and diarrhoea in the conservative group. They concluded that conservative treatment with antibiotics was efficacious in $91 \%$ of cases with a relapse rate of $14 \%$ at 1 year follow-up.

A prospective study by Malik et al comparing antibiotic therapy to appendicectomy in acute appendicitis concluded that conservative treatment was both safe, efficacious and caused 
less patient pain than surgery, minimising the need for analgesia ( $p$ 0.001) (8). They found a relapse rate of $10 \%$ in the conservatively treated group within the first 12 months.

In children with perforated appendicitis who had an appendicectomy the morbidity is around $26-58 \%$ and for conservative management is $0-15 \%$ (23). There is evidence from retrospective studies showing that in patients with perforated appendicitis managed conservatively, the late recurrences showed a mild clinical course (24).

A recent metanalysis comparing conservative management and appendicectomy for complicated appendicitis concluded that conservative management was associated with a significant reduction in wound sepsis, pelvic or intra-abdominal abscesses, small bowel obstruction and need for reoperation (25). In a randomised controlled study by Styrud et al (4), the complication rate in the surgery group was $14 \%$ and was mainly due to infection and the time in hospital, sick leave and time lost from work were 2.6, 6 and 10 days respectively. A study by Anderson reviewing small bowel obstruction after appendicectomy, (13) reported a cumulative risk of surgically treated small bowel obstruction after appendicectomy of $0.41 \%$ after 4 weeks, $0.63 \%$ after 1 year and $1.30 \%$ after 30 years of follow-up, compared with $0.003 \%$ at 1 year and $0.21 \%$ after 30 years of follow-up among a conservatively managed group. In another review of 1,777 patients who had an appendicectomy for acute appendicitis, the overall small bowel obstruction rate was $2.8 \%$ over an average 4.1-year follow-up (26).

Laparoscopic appendicectomy is associated with less postoperative pain and a reduced hospital stay, but it also carries risks as follows: intra-operative complications $(0.7 \%$ to $3.1 \%)$, postoperative complications $(1.9 \%$ to $6.1 \%)$ and re-operation rates ranging from $0.7 \%$ to $3.4 \%$ (27).

A large population based study involving 32,683 patients documented the morbidity and mortality for both laparoscopic and open appendicectomy. (28). Their results for open versus laparoscopic appendicectomy were as follows, respectively: Overall morbidity $(8.8 \%$; $4.5 \%)$ : serious morbidity ( $4 \% ; 2.6 \%)$; surgical site infection $(6.6 \% ; 3.26 \%)$; mortality $(0.13 \%$; $0.07 \%)$; deep incisional SSI $(0.99 \% ; 0.24 \%)$ : Organ space SSI $(1.72 \%$ : $1.79 \%)$; wound disruption ( $0.45 \%$; $0.06 \%)$ : pneumonia ( $0.43 \%$ : $0.24 \%)$; pulmonary embolism $(0.08 \%$ : $0.08 \%)$; sepsis and septic shock $(2.16 \% ; 1.15 \%)$; bleeding $(0.01 \% ; 0.04 \%)$ and UTIs $(0.36 \% ; 0.37 \%)$.

Non-operative management may be cost-effective compared to surgery in a larger number of patients without increasing the risk, and may reduce hospital stay and expenses in both developed and developing countries. However, delayed surgical treatment and a perforated appendix may increase morbidity, time off work and medical expenses. A study by Hansson et al concluded that patients who were managed conservatively had significantly fewer days of sick leave compared to the surgery group. The medical costs were also lower in the conservative group.

\section{Hospital stay}

The length of hospital stay in patients with acute appendicitis managed conservatively is shorter mainly because parenteral administration of antibiotics is necessary probably for only 24 hours. Thereafter, patients can be discharged on oral antibiotics for at least 10 days and follow-up examination scheduled. Studies have shown that antibiotic therapy alone is associated with a significant reduction in the intensity and duration of abdominal pain. (4) Hansson et al. concluded that the number of days with abdominal pain after hospital 
discharge was significantly lower in patients treated conservatively than those who underwent appendicectomy. (3)

Appendicectomy is associated with a significant financial burden both in terms of the operation, hospital charges and days lost from work. Figures from the USA (1997) estimated the overall costs of appendicectomy as one million hospital days and $\$ 3$ billion in hospital charges, of which postoperative complications accounted for half of the hospital charges (29). With the recent increased popularity in laparoscopy, the financial burden is expected to rise even further. In one study, the costs of conservative treatment were $25-50 \%$ less compared to those who underwent surgery (3).

The feasibility of treating appendicitis on an outpatient bases has been facilitated by the increased availability of effective and improved oral antibiotics. The future management of uncomplicated appendicitis could be similar to the current management of uncomplicated diverticulitis, on an outpatient bases. Further cost reductions are expected as a result of elimination of the morbidity and mortality associated with surgery, which is the major contributor of the financial burden.

\section{Negative appendicectomy}

The negative appendicectomy rate recorded in the literature is 15 to $25 \%$ and is associated with significant morbidity such as wound sepsis, small bowel obstruction, pneumonia and incisional hernias. Interestingly, some investigators have found out that the risk of getting small bowel adhesive obstruction is higher in patients who undergo a negative appendicectomy compared to a positive appendicectomy. This underscores the importance of good diagnostic skills in order to reduce the negative appendicectomy rate and the associated morbidity.

The conservative management of acute appendicitis could be more beneficial in peripheral health centres especially in developing countries were resources and facilities might be scarce. This approach can also be useful in busy emergency facilities where it can be used to avoid unnecessary surgery and workload there by diverting resources to real emergency cases and reducing financial burden.

\section{Missing other diagnoses}

The carcinoid tumour is the most common tumour in the appendix with an incidence of 3-7 in every 1000 appendicectomies (30). Carcinoid tumour is commoner in man than women. This tumour can present as acute appendicitis following obstruction of the appendix lumen. Because of their small size they can be missed by imaging. More worrying is the possibility of missing colonic cancer in elderly patients masquerading as an acute appendicitis. Lai et al has shown that the incidence of appendicitis associated with colon cancer is $0.85 \%$ and the interval from appendicectomy to the diagnosis of the cancer was 5.8 months. From this study, the authors recommended that all patients above the age of 40 years presenting with symptoms of acute appendicitis should be investigated for possible underlying colonic cancer. They recommended a colonoscopy at least 6 weeks after surgery especially if the histology of the appendix was normal.

The routine imaging of patients with suspected appendicitis is not cost effective and is not recommended, however, several studies do support selective imaging with improved diagnostic criteria especially when cancer is included in the differential diagnosis $(21,31)$. A 
not uncommon typical scenario is an elderly patient who presents with recurrent right iliac fossa pain and anaemia; in these patients, a caecal tumour may cause obstruction of the appendix lumen resulting in appendicitis. Thus, a high index of colonic cancer should be maintained especially patients more than 40 years of age and those with risk factors for cancer. Conservative management of acute appendicitis can result in missing other diagnosis such as neuroimmune appendicitis (32) resulting in chronic right iliac fossa pains.

\section{Allergy to antibiotics}

The possibility of antibiotics allergic reactions should be borne in mind when a conservative approach is utilised. A good medical and drug history will identify most of these patients. Furthermore, there is a wide variety of types and combinations of antibiotics available which can be used to circumvent this problem. Acute appendicitis is one of the most common surgical conditions and if conservative antibiotic use becomes wide-spread, the possibility of increasing the risk of multidrug antibiotic resistance and susceptibility to resistant bacterial strains can become a major challenge especially if there is no strict adherence to guidelines and protocols. From this point of view, it may not be logical to recommend routine use of antibiotics to such a common surgical condition. This further underscores the importance of aiming for a high diagnostic accuracy for appendicitis before deciding on the use of antibiotics. Antibiotics treatment should be considered following the same high diagnostic accuracy similar to the one required before surgical intervention. This may include use of USS and CT scan of the abdomen. Other authorities in this area have suggested that no patients without an elevated C- reactive protein should be treated for suspected acute appendicitis.

\section{Appendicitis and tubal infertility}

The issue of the possibility of tubal infertility following conservative antibiotic treatment of suspected acute appendicitis has been raised by some investigators. They have reported the rate of tubal infertility to be between 3.2 and $4.8 \%$ (33). However, there is general agreement in the surgical community that a perforated appendix in childhood does not seem to have long-term effects on female fertility. This has important relevance in the management of females of childbearing age group presenting with suspected appendicitis where the practice of low threshold of surgical exploration for fear of increased risk of perforation following a perforation in no longer justifiable.

\section{Patient selection for conservative management}

The current surgical literature clearly supports the role of conservative antibiotic management for a selected group of patients with acute appendicitis. The prerequisites are to aim for a high diagnostic accuracy and to adhere to strict selection criteria in order to achieve the optimum outcome thereby avoiding the problem of negative appendicectomy. The criteria for selecting patients for conservative management of acute appendicitis should be a combination of clinical, laboratory and radiological investigations. Patients with mild clinical signs without complications could be considered for the conservative approach and in the presence of severe clinical features or signs of perforation / peritonitis, surgery should be contemplated unless the patient is unfit for surgery. Surgical intervention should also be 
considered in patients who are initially managed conservatively and then present with recurrent symptoms.

The value of white cell count in the diagnosis of acute appendicitis has been debated over the years and it has been found to be an unreliable marker of severe inflammation. Thus, a normal white cell count level cannot rule out severe acute appendicitis. This is particularly true in patients with immunosuppression, the elderly and paediatrics. . On the other hand CRP has been suggested as a more sensitive and specific marker of the severity of appendiceal inflammation compared to WCC. An elevated CRP is a marker of the degree of advanced pathology and serial CRP measurements has been shown to improve the diagnostic accuracy for acute appendicitis (6).

For conservative treatment to be successful, it is of utmost importance to make a correct diagnosis and assessment as possible so as to institute a correct treatment plan. Routine imaging is not recommended in cases of suspected acute appendicitis, except in atypical presentations. The specificity and sensitivity of CT scan and USS in diagnosing acute appendicitis has been reported as 100 and $97 \%$, and 90 and $76 \%$ respectively (34). CT scan is especially useful in confirming acute appendicitis in paediatric patients and in looking for complications. Diagnostic laparoscopy has a role to play especially in patients with a recurrent history of right iliac fossa pain.

Studies have shown no statistical difference in the postoperative complication rates between primary and conversion cases. However, the duration of hospital stay was significantly higher and thus medical costs might be increased in the conversion cases (35). Thus, predictors for the negative outcome of conservative treatment are important in patient selection. A major concern is diagnostic uncertainty which may result in a negative appendicectomy or a delay in treatment. The presence of an appendiceal faecolith has been found to be associated with a complicated acute appendicitis and a higher recurrence rate after antibiotic therapy, often within the first year of the initial presentation. Thus appendicectomy is often recommended in patients with acute appendicitis associated with a faecolith so as to avoid the possible complications and the risk of recurrences.

An elevated CRP and signs and symptoms of small bowel obstruction have been suggested as possible predictors for a failure of conservative treatment $(36,37)$. Authorities still differ on the significance of a poorly marginated focal mesenteric infiltration as a marker of poor prognosis in the conservative management of appendicitis. Collection size, complexity or the presence of extra-luminal air has not been shown to be significant as predictors of clinical outcome (38). A sound clinical acumen is needed in the assessment of clinical progression of acute appendicitis and decides the need for surgery in the expected $5-10 \%$ subgroup of patients. The use of antibiotics has been shown to delay the need for an emergency operation for at least 24 hours without associated adverse consequences. Antibiotics can be used as a definite treatment of acute appendicitis or as a bridge to surgery, converting an emergency operation to a planned procedure. This applies mostly to paediatric patients who present late at night.

\section{Choice of antibiotics}

Currently there are no strict guidelines or recommendations for the optimal antibiotics treatment for acute appendicitis. Several different types and combinations of antibiotics exist and the choice is mainly affected by availability and surgeon preference. Recent advances in antibiotics therapy have made triple antibiotics regimens for the treatment of 
intra-abdominal infection almost obsolete. Furthermore, the improvements in antibiotics bioavailability has made it possible to treat severe intra-abdominal infections with enteral antibiotics on an outpatient bases. The current non-operative treatment for acute appendicitis involves intravenous antibiotics for a period of 24 to 48 hours followed by oral medication for 10- 12 days as an outpatient and follow-up thereafter.

\section{Interval appendicectomy}

Current opinion is that there is no need for an interval appendicectomy following successful conservative treatment for acute appendicitis even in complicated cases with an abscess or inflammatory mass (39). Recurrences can be managed by a repeat in conservative treatment or observation. Some authorities report that recurrences following conservative treatment tend to follow a milder course (40). It is recommended that appendicectomy should be reserved for multiple recurrences (more than 2) and for those who fail to improve. Interval appendicectomy may prevent recurrent appendicitis in about $7 \%$ of patients presenting with an appendiceal mass. This implies that $93 \%$ of patients may end up with an unnecessary appendicectomy (41).

\section{Summary}

A growing body of evidence supports the role of conservative management of acute appendicitis in carefully selected patients who can be followed-up with close monitoring of the clinical course. Emergency appendicectomy for acute appendicitis may not always be necessary. The success rates range from 68 to 95\%. Other advantages include costeffectiveness, shorter hospital stay, minimal sick leave and less pain. With a diagnostic accuracy rate for acute appendicitis greater than around $71 \%$ to $87 \%$ the conservative management of suspected or proven acute appendicitis seems justified. The recurrence rates are low and the complications are comparable to that after an appendicectomy.

In conclusion, acute uncomplicated appendicitis can be treated successfully with antibiotics with a short duration of hospital stay, minimal sick leave and limited degree and duration of pain. However, the risk of recurrence needs to be compared with the risks of appendicectomy.

\section{References}

[1] Fitz RH. Perforating inflammation of the vermiform appendix. Am J Med Sci 1886; 92: 321-346

[2] Coldrey E. Five years of conservative treatment of acute appendicitis. J Int Coll Surg 1959; 32:255-261

[3] Hansson J, Korner U, Khorram-Manesh A et al. Randomized clinical trial of antibiotic therapy versus appendicectomy as primary treatment of acute appendicitis in unselected patients. Br J Surg 2009; 96: 473-481.

[4] Styrud J, Eriksson S, Nilsson I et al. Appendicectomy versus antibiotic treatment in acute appendicitis. A prospective multicenter randomised controlled trial.World J of Surg 2006; 30:1033-1037.

[5] Eriksson S, Granstrom L. Randomised controlled trial of appendicectomy versus antibiotic therapy for acute appendicitis. Br J Surg 1995; 82: 166-169. 
[6] Luckmann R. Incidence and case fatality rates for acute appendicitis in California: a population-based study of the effects of age. Am J Epidemiol 1989; 129: 905-209.

[7] Migraine S, Atri M, Bret PM et al. Spontaneously resolving acute appendicitis: Clinical and sonographic documentation. Radiology 1997; 205: 205-209.

[8] Malik AA, Bari SU. Conservative management of acute appendicitis. J Gastrointest Surg 2009; 13:966-970.

[9] McPherson A, Kinmonth J. Acute appendicitis and the appendix mass.Br J Surg 1945; 32: 365-370.

[10] Anonymous. Combined traditional Chinese and Western medicine in acute appendicitis. Chin Med J 1977; 3: 266-269.

[11] Adams ML. The medical management of acute appendicitis in a non-surgical environment: a retrospective case review. Milit Med 1990; 155:345-347.

[12] Tingstedt B, Johansson J, Nehez L et al. Late abdominal complaints after appendicectomy -readmissions during long-term follow-up. Dig Surg 2004; 21:2327.

[13] Anderson RE. Small bowel obstruction after appendicectomy. Br J Surg 2001; 88: 13871391.

[14] Anderson RE. The natural history and traditional management of appendicitis revisited: spontaneous resolution and predominance of prehospital perforations imply that a correct diagnosis is more important than an early diagnosis. World J Surg 2007; 31:86-92.

[15] Mui LM, Ng CS, Wong SK et al Optimum duration of prophylactic antibiotics in acute non-perforated appendicitis. Aust N Z J Surg 2005; 75: 425-428.

[16] Winslow RE, Dean RE, Harley JW. Acute non-perforating appendicitis. Arch Surg 1983; 118: 651- 655.

[17] Blomqvist P, Ljung H, Nyren O et al. Appendectomy in Sweden 1989-1993 assessed by the Inpatient Registry. J Clin Epidemiol 1998; 51: 859-865.

[18] Hale DA, Molloy M, Pearl RH et al. Appendicdctomy: A contemporary appraisal. Ann Surg 1997; 225: 252-261.

[19] Bijnen CL, van den Broek WT, Bijnen AB et al. Implications of removing a normal appendix. Dig Surg 2003; 20:215-221.

[20] Heller MB, Skolnick ML. Utrasound documentation of spontaneously resolving appnedcitis. Am J Emerg Med 1993; 11:51-53.

[21] Varadhan KK, Jumes DJ, Neal KR et al. Antibiotic therapy versus appendectomy for acute appendicitis: a meta-analysis. World J Surg 2010; 34: 199-209.

[22] Wiegering VA, Kellenberger CJ, Bodmer N et al. Conservative management of acute appendicitis in children with haematologic malignancies during chemotherapyinduced neutropaenia. J pediatr Hematol Oncol 2008; 30: 464-467

[23] Abes M, Etik B, Kazil S. Non-operative treatment of acute appendicitis in children.J Pediat Surg 2007;42:1439-1442.

[24] Anderson RE, Petzold MG. Nonsurgical treatment of appendiceal abscesses or phlegmon: a systematic review and meta-analysis. Ann Surg 2007; 246:741-748

[25] Simillis C, Symeondes P, Shorthouse AJ et al. A meta-analysis comparing conservative treatment versus acute appendicicectomy for complicated appendicitis (abscess or phlegmon). Surgery 2010; 147: 818-829. 
[26] Leung TT, Dixon E, Gill M et al. Bowel obstruction following appendicectomy: what is the true incidence? Ann Surg 2009; 250:51-52

[27] Brugger L, Rosella L, Candinas D et al. Improving outcomes after laparoscopic appendectomy: a population-based 12-year trend analysis of 7446 patients. Ann Surg. Published online first: 17 December 2010. Doi: 10.1097/SLA.0b013e3181fc9d53.

[28] Ingraham AM, Cohen ME, Bilimoria KY et al. Comparison of outcomes after laparoscopic versus open appendectomy for acute appendicitis at 222 NSQIP hospitals. Surgery 2010; 148:625-635; discussion 635-637.

[29] Davis GM, Dasbach EJ, Teutsch S. The burden of appendicitis-related hospitalisations in the United States in 1997. Surg Infect (Larchmt) 2004; 5:190:950-954

[30] Roggo A, Wood WC, Ottinger LW. Carcinoid tumours of the appendix. Ann Surg 1993; 217:385-390.

[31] Augustin T, Bhende S, Chavda K et al. CT scans and acute appendicitis: a five-year analysis from a rural teaching hospital. J Gastrointest Surg 2009; 13: 1306-1312.

[32] Franke C, Gerharz CD, Bohner H et al. Neurogenic appendicopathy: a clinical disease entity? Int J Colorectal Dis 2002; 17:185-191

[33] Mueller BA, Daling JR, Moore DE et al. Appendectomy and the risk of tubal infertility. N Engl J Med 1986; 315:1506-1508.

[34] Horton MD, Counter SF, Florence MG et al. A prospective trial of computed tomography and ultrasonography for diagnosing appendicitis in the atypical patient. Am J Surg 2001; 182:305-306

[35] Shindoh J, Hiwa H, Kawai K et al. Predictive factors for negative outcomes in initial non-operative management of suspected appendicitis. J Gastrointest Surg 2010; 14: 309-314

[36] Nadler EP, Reblock KK, Vaughan KG et al. Predictors of outcome for children with perforated appendicitis initially treated with nonoperative management. Surg Infect 2004; 5: 349-356.

[37] Kogut KA, Blakely ML, Schropp KP et al. The associationof elevated percent bands on admission with failure and complications of interval appendectomy. J Pediatr Surg 2001; 36:165-168

[38] Levi T, Whyte C, Borzykowsi $\mathrm{R}$ et al. Nonoperative management of perforated appendicitis in children: can CT predict outcome? Pediatr Radiol 2007; 37: 251-255.

[39] Eriksson S, Styrud J. Interval appendicectomy: a retrospective study. Eur J Surg 1998; 164: 771-775.

[40] Dixon MR, Haukoos JS, Park IU et al. An assessment of the severity of recurrent appendicitis. Am J Surg 2003; 186: 718-722

[41] Tekin A, Kurtoglu HC, CanI et al. Routine interval appendectomy is unnecessary after conservative treatment of appendiceal mass. Colorectal Dis 2008; 10:465-468 


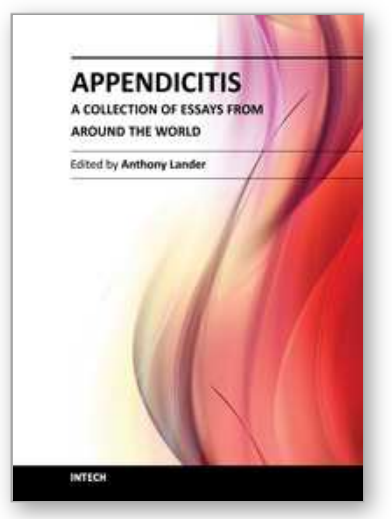

\author{
Appendicitis - A Collection of Essays from Around the World \\ Edited by Dr. Anthony Lander
}

ISBN 978-953-307-814-4

Hard cover, 226 pages

Publisher InTech

Published online 11, January, 2012

Published in print edition January, 2012

This book is a collection of essays and papers from around the world, written by surgeons who look after patients of all ages with abdominal pain, many of whom have appendicitis. All general surgeons maintain a fascination with this important condition because it is so common and yet so easy to miss. All surgeons have a view on the literature and any gathering of surgeons embraces a spectrum of opinion on management options. Many aspects of the disease and its presentation and management remain controversial. This book does not answer those controversies, but should prove food for thought. The reflections of these surgeons are presented in many cases with novel data. The chapters encourage us to consider new epidemiological views and explore clinical scoring systems and the literature on imaging. Appendicitis is discussed in patients of all ages and in all manner of presentations.

\title{
How to reference
}

In order to correctly reference this scholarly work, feel free to copy and paste the following:

Inchien Chamisa (2012). What Is the Role of Conservative Antibiotic Treatment in Early Appendicitis?, Appendicitis - A Collection of Essays from Around the World, Dr. Anthony Lander (Ed.), ISBN: 978-953-307814-4, InTech, Available from: http://www.intechopen.com/books/appendicitis-a-collection-of-essays-fromaround-the-world/what-is-the-role-of-conservative-antibiotic-treatment-in-early-appendicitis-

\section{INTECH}

open science | open minds

\author{
InTech Europe \\ University Campus STeP Ri \\ Slavka Krautzeka 83/A \\ 51000 Rijeka, Croatia \\ Phone: +385 (51) 770447 \\ Fax: +385 (51) 686166 \\ www.intechopen.com
}

\author{
InTech China \\ Unit 405, Office Block, Hotel Equatorial Shanghai \\ No.65, Yan An Road (West), Shanghai, 200040, China \\ 中国上海市延安西路65号上海国际贵都大饭店办公楼 405 单元 \\ Phone: +86-21-62489820 \\ Fax: +86-21-62489821
}


(C) 2012 The Author(s). Licensee IntechOpen. This is an open access article distributed under the terms of the Creative Commons Attribution 3.0 License, which permits unrestricted use, distribution, and reproduction in any medium, provided the original work is properly cited. 